\title{
Interdisciplinary Mathematics for Environmental Engineers
}

\author{
Richard J. Jardine \\ United States Military Academy
}

\begin{abstract}
Cooperation between the Department of Geography\& Environmental Engineering and the Department of Mathematical Sciences at the United States Military Academy at West Point has led to the development of an elective course taught by the latter department tailored to the needs of the former. Unlike the situation at many research universities, where engineering departments develop math courses within their own programs, the encouragement of interdisciplinary activities at West Point has created a collegiality that enhances the overall undergraduate engineering education. The course MA366, Vector Calculus and Introduction to Partial Differential Equations, completes the mathematical foundation which supports subsequent study of environmental engineering. This paper addresses the development and implementation of the course, which accentuates hydrogeologic applications. Emphasis in this paper is placed on the cooperative efforts of the departments involved and course activities. Suggestions for further course improvements are included.
\end{abstract}

\section{Introduction}

Far too often, undergraduates look on their courses as individual hurdles that must be cleared on the way to graduation. It is preferable that students view their work over four years as a continuum. Intentional activities are necessary to prevent discretization of the learning process. Engineering students in the traditional curriculum understand that mathematics courses are prerequisites, but often fail to make the appropriate connection between the calculus and subsequent engineering courses. A connected undergraduate engineering curriculum which uses interdisciplinary applications to bind courses and departments together can make the undergraduate engineering education a continuous and more efficient process. This view is a distinct contrast to the discrete set of sometimes disjoint or redundant courses offered at many universities.

This paper describes an interdisciplinary effort involving an engineering department and the mathematics department at the United States Military Academy (USMA) at West Point. What makes this activity special is the cooperation between departments in the development of the mathematics course, a situation which is in contrast to the more common practice of engineering departments developing their own mathematics courses. The focus of the interdisciplinary effort described here is on the development of the content of the mathematics course and the use of a project to tie the two courses together. In addition to addressing those two subjects, this paper discusses further steps across the bridge transcending traditional course and departmental boundaries. The cooperative efforts presented prevent inefficient replication of course 
content. More important, these activities make it easier for students to see the connection between the mathematics and the engineering subject, enhancing their motivation and ability to learn both,

\section{Course Development}

The engineering course for which the mathematics course is a prerequisite is the senior-level EV394 Hydrogeology. The course covers the movement of groundwater, fluid flow through porous media, and the transport of chemical contaminants in the fluid flow from a perspective consistent with the principles of hydraulic engineering. Computer modeling of hydrogeological phenomena is a significant component of the course. The text for the course assumes the student has a mathematical background through partial differential equations. As the core mathematics sequence at West Point provides preparation through multivariable calculus and ordinary differential equations, an additional course was needed to ready students for the engineering course.

The additional course was developed through collaboration between the Department of Geography and Environmental Engineering and the Department of Mathematical Sciences at USMA. The general content of the course includes vector calculus and both analytical and numerical methods for the solution of partial differential equations. Because of the interdepartmental cooperation, MA366 Vector Calculus and Introduction to Partial Differential Equations has been an effective service course.

A quote taken from the hydrogeology text is used in the first lesson of the mathematics course. The authors make it clear that, for the study of hydrogeology, the "main language is mathematics."1 The subject of hydrogeology is rich with applications of vector calculus and partial differential equations that are certainly within the grasp of undergraduates. Vector functions of one variable are developed to model streamlines of fluid flow through the soil. Line integrals are evaluated to determine flow rates. Fluid potential is applied in the discussion of conservative fields. Students discover the advantages of using the classical theorems of Green, Gauss and Stokes to calculate the line and surface integrals arising from the applications. The concepts of divergence and curl have obvious relevance to the flow and circulation of subsurface water. Vector calculus topics are readily motivated by these and other applications taken from hydrogeology. In turn, students are motivated to learn the mathematics as they clearly see the relation to their engineering studies.

The partial differential equations (PDEs) which model fluid transport in porous media, contamination in aquifers, and steady-state hydraulic head are developed applying the divergence theorem. The development of boundary conditions is accomplished through discussion of subsurface geology. Solutions of the boundary value problems are obtained analytically through the use of Fourier's method and numerically using finite-difference methods. Time-dependent and steady-state problems are solved both numerically and analytically. The limitations and advantages of using either, solution technique are discovered by the students in exercises and the course project.

Presented with PDEs for which separation is not possible, numerical methods are selected as an alternative approach. Considerations of stability, accuracy, and computational efficiency of numerical schemes are explored by the students in solving the advection-diffusion equation. In the engineering course, a hybrid finite-difference/finite-element package is used to solve more complex problems. The work done in the mathematics precursor makes the computer package appear less like a "black box" to the students than it otherwise would. 


\section{Interdisciplinary Project}

The students use the Saturated-Unsaturated TRAnsport (SUTRA) simulation mode $1^{2}$ to solve a design problem in the hydrogeology course. The stage is set for that work by a project based on the same scenario and presented to students on the first day of the mathematics course. This interdisciplinary project is another thread which connects the courses. In the mathematics course, students complete the project in three phases. The first part includes applications of the vector calculus; the second, analytical solution of PDEs; and the third, numerical solution of a more realistic problem, the advection-diffusion equation, which is not solvable by the analytical method. On completion of the last part of the mathematics project, the students are better able to understand the principles behind the simulation package that is used to obtain a solution to the two-dimensional, steady-state problem presented in the engineering course. On completing the design problem, students have finished a task which began a semester earlier in the mathematics course.

The continual dialogue between instructors of the two courses as the students work on the interdisciplinary project is exceptionally beneficial. The engineer has a better understanding of student preparation prior to the course and knows the language students have learned. The meetings between instructors ensure the use of a common notation and terminology, increase collegiality, and reduce frustrations about what students are learning in other departments. The mathematician is able to study and use the applications as a motivator for students. Engineering students crave real-world applications of the mathematics they are required to study. The mathematics instructor, who also teaches multivariable calculus, is better prepared to present applications in the mathematics classroom and to articulate to mathematics colleagues the requirements of the engineering department. The service role of the mathematics program is performed with greater effectiveness.

\section{Conclusion}

The interdisciplinary efforts have improved the quality of the engineering education, but there is more that can be done to bridge the gap. A next step in this process is team-teaching. At this point only one lesson is shared of the 80 in the two courses. Further dialogue is underway to increase that number significantly. Both departments see great value in interjecting the mathematics instruction "in-time." An approach incorporating that view is to team-teach the courses as a two-semester sequence based on engineering applications, interspersed with mathematics instruction as needed.

Through this interdisciplinary activity, the undergraduate engineering curriculum is seen as a continuum rather than a discrete collection of courses. The cooperation between departments reduces inefficiencies in work required of students and faculty and prevents such hurdles to student learning as abuses of notation, inconsistent terminology, and lack of instructor awareness of the level of student understanding of key concepts. The environment in which students find themselves after graduation is truly "interdisciplinary," and it is appropriate that we in academe demonstrate the effectiveness of cooperative efforts.

\section{References}

1. Domenico, Patrick A. and F. W. Schwartz, Physical and Chemical Hydrology. John Wiley\& Sons, 1990, p.2. 
2. Voss, Clifford I. , A finite-element simulation model for saturated-unsaturated fluid-density-dependent groundwater flow with energy transport or chemically-reactive single-species solute transport. US Geological Survey Water-Resources Investigations Report 84-4369, 1984.

\section{RICHARD J. JARDINE}

Lieutenant Colonel Dick Jardine, United States Army, is an assistant professor of mathematics at the United States Military Academy, West Point, New York. His a 1975 graduate of West Point and completed his Ph.D. at Rensselaer Polytechnic Institute in 1994. He currently teaches numerical analysis, multivariable calculus, and the course described above. In his spare time, he trains for the Boston Marathon. 